Article

\title{
Improved Formation Kinetics of Carbon Dioxide Hydrate in Brine Induced by Sodium Dodecyl Sulfate
}

\author{
Lu Liu ${ }^{1,2}$, Yuanxin Yao ${ }^{1}$, Xuebing Zhou ${ }^{1}{ }^{1}$, Yanan Zhang ${ }^{1}$ and Deqing Liang ${ }^{1, *}$ \\ 1 Key Laboratory of Gas Hydrate, Guangzhou Institute of Energy Conversion, Chinese Academy of Sciences, \\ Guangzhou 510640, China; llu1997@mail.ustc.edu.cn (L.L.); yaoyx@ms.giec.ac.cn (Y.Y.); \\ zhouxb@ms.giec.ac.cn (X.Z.); zhangyn@ms.giec.ac.cn (Y.Z.) \\ 2 Nano Science and Technology Institute, University of Science and Technology of China, Hefei 230027, China \\ * Correspondence: liangdq@ms.giec.ac.cn; Tel./Fax: +86-20-87057669
}

check for updates

Citation: Liu, L.; Yao, Y.; Zhou, X.; Zhang, Y.; Liang, D. Improved Formation Kinetics of Carbon Dioxide Hydrate in Brine Induced by Sodium Dodecyl Sulfate. Energies 2021, 14, 2094. https://doi.org/ $10.3390 /$ en14082094

Academic Editor: Devinder Mahajan

Received: 12 January 2021

Accepted: 6 April 2021

Published: 9 April 2021

Publisher's Note: MDPI stays neutral with regard to jurisdictional claims in published maps and institutional affiliations.

Copyright: (C) 2021 by the authors. Licensee MDPI, Basel, Switzerland. This article is an open access article distributed under the terms and conditions of the Creative Commons Attribution (CC BY) license (https:// creativecommons.org/licenses/by/ $4.0 /)$.

\begin{abstract}
Due to high efficiency and low cost, hydrate-based desalination is investigated as a pretreatment method for seawater desalination. To improve the formation rate of hydrates, the effect of sodium dodecyl sulfate (SDS) on $\mathrm{CO}_{2}$ hydrate formation from a $3.5 \mathrm{wt} \% \mathrm{NaCl}$ solution was measured at $275 \mathrm{~K}$ and $3 \mathrm{MPa}$. X-ray diffraction (XRD) and cryo-scanning electron microscopy (cryo-SEM) were used to measure the crystal structure and micromorphology of the formed hydrates. The results showed that the induction time of $\mathrm{CO}_{2}$ hydrate formation reduced from 32 to 2 min when SDS concentration increased from 0.01 to $0.05 \%$, the hydrate conversion rate increased from 12.06 to $23.32 \%$, and the remaining $\mathrm{NaCl}$ concentration increased from 3.997 to $4.515 \mathrm{wt}$.\%. However, as the SDS concentration surpassed $0.05 \mathrm{wt} . \%$, the induction time increased accompanied by a decrease in the hydrate conversion rate. XRD showed that the $\mathrm{CO}_{2}$ hydrate was a structure I hydrate, and SDS had no influence on the hydrate structure. However, cryo-SEM images revealed that SDS promoted the formation of hydrates by increasing the specific surface area of the formed hydrates and folds; rods and clusters could be found on the surface of the $\mathrm{CO}_{2}$ hydrate. Thus, the best SDS concentration for promoting $\mathrm{CO}_{2}$ hydrate formation was approximately $0.05 \mathrm{wt}$.\%; desalination was most efficient at this concentration.
\end{abstract}

Keywords: desalination; hydrate; sodium dodecyl sulfate

\section{Introduction}

With the rapid development of industry and agriculture, shortage of fresh water has become one of the most common problems globally and is likely to worsen in the coming decades [1]. The Earth is abundant in seawater, which accounts for $97.5 \mathrm{wt} . \%$ of the total water resources [1]. Seawater desalination is, thus, considered as the core technology for solving the shortage of freshwater resources [2]. Traditional desalination technologies, such as multistage flash (MSF) and reverse osmosis (RO), are sufficiently mature [3]. However, more research is required to improve the technology and reduce the cost of the process [4].

Gas hydrates are nonstoichiometric crystals formed from water and guest molecules, such as methane $\left(\mathrm{CH}_{4}\right)$ and carbon dioxide $\left(\mathrm{CO}_{2}\right)$, at a low temperature and high pressure [5]. Seawater desalination by the hydrate method is similar to seawater desalination by the freezing method. Fresh water can be obtained through the removal of salt during hydrate formation. Although the hydrate-forming conditions are relatively harsh, the latent heat in the conversion from liquid to hydrate is smaller than thermal desalination, the operating pressure is lower than that of reverse osmosis, and it is not sensitive to seawater quality. Therefore, it can be used as a pretreatment method for seawater desalination. Han et al. [6] systematically introduced the pretreatment method of $\mathrm{CO}_{2}$ hydrate as a refrigerant (hydrate-induced ice desalination, HIID) as a seawater RO process.

Hong [7] compared the application of three cyclic compounds in the hydrate-based desalination (HBD) process, and thermodynamic and kinetic experiments showed that 
cyclopentane was more effective. Han [8] selected cyclopentane (CP) to study the desalting process of hydrate formation, and the results showed that single-stage hydrate formation followed by filtration could remove $63 \%$ of the salt ions. Cha and Seol [9] proposed a gas hydrate-based desalination process; cyclopentane and cyclohexane were selected as guest molecules to reduce the formation temperature of hydrates and improve the formation kinetics of hydrates. Zhou [10] determined the formation of $\mathrm{CP}$ and $\mathrm{CO}_{2}$ hydrates by XRD and macroscopic methods, and the results showed that the appropriate initial pressure and $\mathrm{CP}$ mass fraction should be approximately 2.5 and $0.2 \%$, respectively. The results show that the two hydrate systems can improve desalting efficiency. Babu et al. [11,12] separated the resulting solid hydrate from concentrated brine and proposed a new design using LNG cold energy to improve the recovery rate of hydrated salt. He et al. [13], based on ColdEn-HyDesal analysis of LNG cold energy, discussed the effects of recovery pressure, water recovery rate, and concentration of $\mathrm{NaCl}$ in seawater on the desalination process. Kang et al. [14] studied the removal rates of salt anions in seawater samples using the HBD process.

$\mathrm{CO}_{2}$ is a well-known greenhouse gas; therefore, it is a perfect choice as a guest molecule. Babu et al. [15] reported innovative ways to desalinate water while capturing $\mathrm{CO}_{2}$ by $\mathrm{CO}_{2}$ hydrate formation. Improving the hydrate formation rate is an important issue that remains to be solved. Linga [16] outlined a series of non-surfactant-based methods to increase hydrate formation rates, such as hydrogels, dry water, silica gels, foams, nanoparticles, and sand packs. Li et al. [17] found that $0.028 \mathrm{~mol} \%$ DTAC greatly reduced the induction time of hydrate formation and showed the best carbon capture efficiency.

Surfactants are widely used in hydrate-based technologies as hydrate promoters. Torre et al. [18] studied the kinetics of $\mathrm{CO}_{2}$ hydrate formation using SDS and THF. Zhang et al. [19] noted that the addition of a small amount of CP under static conditions promoted hydrate growth. Arora et al. [20] found that rhamnolipids could be used as an environmentally friendly biological surfactant to promote hydrate growth with a rhamnolipid concentration of $0.1 \mathrm{wt} . \%$. Zhou [21] used in situ Raman and macroscopic methods to study the use of solid tetra-n-butyl ammonium bromide hydrate for carbon capture, and showed that increasing the temperature and specific surface area of hydrate particles were beneficial to $\mathrm{CO}_{2}$ release.

SDS is a common anionic surfactant that promotes hydrate formation. Han and Wang [22] added SDS to the NGH reaction system and noted that the surface tension of the solution after the addition of SDS was greatly reduced, leading to a greatly accelerated rate at which gas molecules entered the liquid phase, thus accelerating the rate of hydrate formation. The hydrate growth rate increased by at least $42.97 \mathrm{wt} . \%$, while the induction time was reduced by $22.63 \mathrm{wt} . \%$. Jiang et al. [23] found that $0.5 \mathrm{~g} / \mathrm{L}$ SDS and $0.3 \mathrm{~g} / \mathrm{L}$ SDBS solutions induced $\mathrm{CO}_{2}$ hydrate formation in approximately $35 \mathrm{~min}$ at $274.15 \mathrm{~K}$ and 5.0 MPa initial pressure; SDS and SDBS can greatly enhance the stability of $\mathrm{CO}_{2}$ hydrate. Molokitina et al. [24] found that the conversion rate of $\mathrm{CO}_{2}$ hydrate was $90 \mathrm{wt} . \%$ when $0.1 \%$ SDS was added under static conditions. Dicharry et al. [25] showed that SDS promoted the formation kinetics of hydrate and hydrate production. Gayet et al. [26] observed that hydrate crystals mainly grow on the inner wall of a transparent reactor in the form of a porous structure. Link et al. [27] systematically studied the effects of a series of surfactants on the hydrate growth rate and gas storage and concluded that SDS might be the most suitable surfactant to promote hydrate formation, and the gas absorption could surpass $97 \mathrm{wt} . \%$ in the presence of SDS. To investigate the promoting effect of SDS on hydrate formation, Kang et al. [28] found that in the presence of SDS, the initial hydrate formation rate increased gas consumption and promoted the growth of hydrate, but excessive SDS inhibited hydrate growth. Therefore, if the surfactant concentration surpassed a certain extent, the hydrate rate tended to be inhibited. Zhang et al. [29] reported that SDS could reduce the induction time of $\mathrm{CH}_{4}$ hydrate formation but found no systematic trend in the range of 260 to $1000 \mathrm{ppm}$. Torre et al. [30] placed THF and SDS into a high-pressure intermittently stirred reactor to study the kinetics of $\mathrm{CO}_{2}$ hydrate formation experiments 
and found that it had a significant effect on $\mathrm{CO}_{2}$ capture. In summary, the use of surfactants as accelerators in hydrate formation is of great significance in hydrate research.

X-ray diffraction (XRD) and cryo-scanning electron microscopy (cryo-SEM) are effective tools to reveal the microscopic properties of hydrate growth. SEM was used to measure the micro-morphology. In previous work, SEM is known as an effective tool to reveal the evident change in hydrate surface as the additives such as ionic salts or surfactants were added in the aqueous phase. For example, hydrate crystals grown from $\mathrm{NaCl}$ solution had a relatively compact and smooth surface [31], while hydrate growth from the solution containing surfactants usually have a different morphology, which greatly enlarge the specific surface area of hydrate crystals [32]. Since the growth rate of a hydrate nuclei is determined by the surface area so that the measurement of hydrate micro-morphology would reveal the mechanism of additive on hydrate growth [33]. XRD patterns are used to identify the crystal structure of formed hydrates. In previous work, the sI and sII hydrate were found to coexist during crystallization, although the hydrate-forming gas was restricted to one type such as methane [34]. In addition, the pressure was also reported to influence the hydrate structure as the additives were added [35]. In this case, it would be necessary to determine the hydrate structure that formed from SDS solutions.

In this work, the kinetics of $\mathrm{CO}_{2}$ hydrate formation from $\mathrm{NaCl}$ solutions in the presence of SDS concentrations ranging from 2 to $5 \mathrm{wt}$.\% were measured. The gas consumption and pressure change were used to evaluate $\mathrm{CO}_{2}$ hydrate growth. Microscopically, the cage structure of $\mathrm{CO}_{2}$ hydrate was tested by X-ray diffraction (XRD); the surface morphology and characteristics of the hydrate samples under microscopic conditions were tested by cryo-scanning electron microscopy (cryo-SEM).

\section{Experimental}

\subsection{Experimental Materials and Apparatus}

The chemical reagents used in this study are listed in Table 1. All the chemicals were used without further purification.

Table 1. List of experimental materials.

\begin{tabular}{cccc}
\hline Reagent & Molecular Formula & Purity & Supplier \\
\hline $\begin{array}{c}\text { Sodium dodecyl } \\
\text { sulfate (SDS) }\end{array}$ & $\mathrm{C}_{12} \mathrm{H}_{25} \mathrm{O}_{4} \mathrm{NaS}$ & $99.0 \mathrm{wt} \%$ & $\begin{array}{c}\text { Macklin Company, } \\
\text { (Shanghai, China) }\end{array}$ \\
Sodium chloride & $\mathrm{NaCl}$ & $99.5 \mathrm{wt} \%$ & $\begin{array}{c}\text { Guangzhou Yuejia Gas } \\
\text { Carbon dioxide }\end{array}$ \\
Co & $\mathrm{CO}_{2}$ & $\begin{array}{c}\text { Electrical resistivity } \\
18.2 \mathrm{~m} \Omega \cdot \mathrm{cm}^{-1}\end{array}$ & Made in laboratory \\
\hline
\end{tabular}

The experimental device used in this study is shown in Figure 1. The main part of the device was a high-pressure reaction kettle and a buffer tank made of 316 stainless steel. The volumes of the high-pressure reaction kettle and buffer tank were 98 and $306 \mathrm{~mL}$, respectively. The high-pressure reaction kettle and buffer tank were equipped with a pressure sensor (CYB-20S) supplied by Beijing Westport AviC Technology Co., Ltd. (Beijing, China) and a thermal resistance PT100, respectively. The range of the thermocouple is -223.15 to $\sim 223.15 \mathrm{~K}$, and the accuracy is $\pm 0.1 \mathrm{~K}$. The measuring range of the pressure sensor was 0-20 MPa, the precision was $\pm 1 \mathrm{kPa}$, the pressure supply was $24 \mathrm{VDC}$, and the output was 0.5 VDC. The high-pressure reaction kettle and buffer tank were placed in the thermostatic control system of the THD-2030 water bath. The cooling medium in the tank was an aqueous solution of ethylene glycol, which was purchased from Macklin Company with a purity of $98 \mathrm{wt} . \%$. The temperature and pressure data in the experiment were collected using an Agilent 34970A collection system provided by Agilent Technology Co. Ltd. (Shenzhen, China), and the data were collected every $10 \mathrm{~s}$. An H03-A magnetic 
stirrer was installed below the high-pressure reaction kettle, which was purchased from Shanghai Meiyingpu Instrument Manufacturing Co. Ltd. (Shanghai, China).

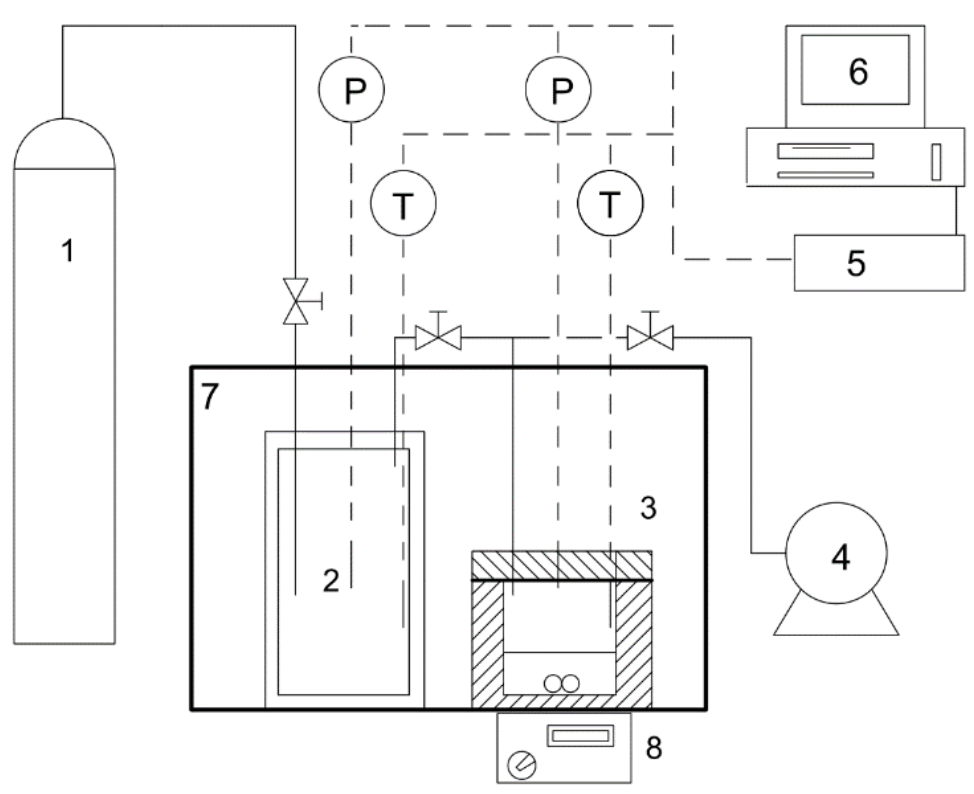

Figure 1. Schematic diagram of $\mathrm{CO}_{2}$ hydrate forming device. 1 Gas cylinder; 2 buffer tank; 3 highpressure kettle; 4 vacuum pump; 5 data collector; 6 computer; 7 thermostatic bath; 8 magnetic stirrer.

\subsection{Experimental Section}

\subsubsection{Macroscopic Measurements}

Before beginning the experiment, the airtightness of the high-pressure reaction kettle was checked, along with the position of the main sealing port and the connecting pipe valve between the soap water and the high-pressure reaction kettle. If there was a foaming phenomenon, the location and cause of the air leak were determined and repaired in time. After the repair, the leak was checked again until there was no foaming phenomenon when the soap water was sprayed. The reactor and buffer tank were purged with deionized water three times, and $30 \mathrm{~mL}$ of the prepared solution was loaded into the reactor. Then, the reactor and buffer tank were sealed, connected, evacuated, and immersed in a water bath. Subsequently, $\mathrm{CO}_{2}$ was loaded into the buffer tank. When the temperature of the reactor remained stable at $275.15 \mathrm{~K}, \mathrm{CO}_{2}$ in the buffer tank was injected up to $1 \mathrm{MPa}$, and the magnetic stirrer was turned on to dissolve the gas in the solution and run at a speed of $750 \mathrm{rpm}$. As the temperature stabilized again, the magnetic stirrer was switched off, and $\mathrm{CO}_{2}$ in the buffer tank was injected into the reactor up to $3 \mathrm{MPa}$. Finally, the stirrer was turned on again, which was defined as the start of hydrate formation. After a reaction period, when the pressure drop in the reactor was less than $0.1 \mathrm{MPa}$, the hydrate was considered to be finished. In each experiment, the temperature and pressure data were recorded every $10 \mathrm{~s}$.

\subsubsection{Data Processing}

During the experiment, the gas consumption is the difference between the amount of substances in the gas at the initial time and the amount of substances in the gas in the reactor at time $t$. The gas consumption for $\mathrm{CO}_{2}$ hydrate growth at time $\mathrm{t}$ can be calculated as follows:

$$
\Delta\left(n_{r}\right)_{t}=n_{r, 1}-n_{r, t}=\frac{P_{r, 1} V_{g a s}}{Z_{r, 1} R T_{r, 1}}-\frac{P_{r, t} V_{g a s}}{Z_{r, t} R T_{r, t}}
$$

where $n_{r, 1}$ is the number of moles of gas in the reactor at the initial time, and $n_{r, t}$ is the number of moles of gas in the reactor at time $t(\mathrm{~mol}) . V_{\text {gas }}$ is the volume of free gas in 
the reactor. $R$ is the gas constant, which is $8.3145 \mathrm{~J} \cdot \mathrm{mol}^{-1} \cdot \mathrm{K} . \mathrm{Z}$ is the compression factor calculated from Pitzer's correlation 25, as follows:

$$
\mathrm{P}=\frac{R T}{V_{m}-b}-\frac{a \alpha}{V_{m}+2 b V_{m}-b^{2}}
$$

In the formula, $a=\frac{0.45724 R^{2} T_{c}^{2}}{P_{c}} ; b=\frac{0.07780 R T_{c}}{P_{c}}$; where the compression factor can be determined as follows: $\alpha=\left[1+\left(37464+1.54226 \omega-0.26992 \omega^{2}\right)\left(1-T_{r}^{0.5}\right)\right]^{2}$

$$
Z=\frac{P V_{m}}{R T}
$$

$V_{m}$ is the molar volume of $\mathrm{CO}_{2}, P_{c}$ is the critical pressure, $T_{c}$ is the critical temperature, $\omega$ is the eccentric factor $(0.0115)$, and $T_{\mathcal{C}}$ is the relative temperature.

The conversion rate of water is:

$$
C_{w}=\frac{n \Delta n_{r} M_{\mathrm{H}_{2} \mathrm{O}}}{m} \times 100 \%
$$

where $n$ is the hydration number of $\mathrm{CO}_{2}$ hydrate (6.627), $m$ is the mass of water in the reactor, which is $30 \mathrm{~g} ; \mathrm{M}_{\mathrm{H}_{2} \mathrm{O}}$ is the molar mass of water.

Since the $\mathrm{CO}_{2}$ solubility in aqueous phase was significant, which could not be neglected, the gas dissolved in liquid phase, which was not participated in hydrate growth. In this case, the initial time of gas consumption calculation was set at the end of the hydrate nucleation stage in typical hydrate formation. As for the hydrate formation where the nucleation stage could be neglected. The averaged value of pressure decrease from the initial of hydrate formation to the end of hydrate nucleation in the other typical hydrate formation was adopted to evaluate the gas dissolved in liquid phase, which was not participated in hydrate growth.

\subsubsection{Microscopic Measurements}

The $\mathrm{CO}_{2}$ hydrate prepared for macroscopic measurements was quickly removed, and each sample was preserved in a liquid nitrogen tank to prevent hydrate decomposition. The micro experiments in this study were mainly XRD and cryo-SEM.

XRD test: XRD was performed using a powder X-ray diffractometer X Pert Pro MPD, which was provided by Panacco in the Netherlands. The light source was a Cu target, the wavelength of the incident light was $10-80^{\circ}$, and the step length was $0.0167^{\circ}$. The test temperature used in the experiment was $-180^{\circ} \mathrm{C}$. The sample was placed flat on the sample table. Thereafter, the cold table and the door of the XRD were quickly closed and tested using computer control software (HighScore Plus, produced by PANalytical B. V., Almelo, The Netherlands).

Cryo-SEM test: Cold field emission (frozen) scanning electron microscopy (S-4800) was provided by Hitachi LTD., (Tokyo, Japan). Before the test, the equipment was vacuumed, and the entire process was approximately $1.5 \mathrm{~h}$. Once the vacuum degree reached $0.001 \mathrm{~Pa}$, the requirements of high pressure and temperature reduction in the instrument can be fulfilled. Thereafter, equipment was connected with liquid nitrogen to cool it down to $88 \mathrm{~K}$ and begin the sample preparation. The hydrate samples, which were preserved in liquid nitrogen, were first ground in liquid nitrogen, and a small amount of sample was wrapped in aluminum foil and placed on a copper sample stage, which was then placed in the sample room to open the aluminum foil. Aluminum foil was used to prevent water vapor in the air from condensing on the sample surface during sample transfer. Finally, the sample was exposed to an electron beam of SEM to obtain SEM images. 


\section{Results and Discussion}

\subsection{Macroscopic Experiments}

The $\mathrm{CO}_{2}$ hydrates in this study were performed in isochoric systems. Figure 2 shows the pressure and temperature changes in $\mathrm{CO}_{2}$ hydrate formation by adding $0.01,0.02,0.05$, 0.07 , and $0.10 \% \mathrm{SDS}$ in a $3.5 \mathrm{wt} . \% \mathrm{NaCl}$ solution. A typical hydrate formation process, which contained a nucleation stage followed by a hydrate growth stage, was observed in the solution with $0.01,0.02,0.05 \mathrm{wt} . \%$ SDS. In the nucleation stage, the pressure decreases rapidly, which is mainly caused by the rapid dissolution of $\mathrm{CO}_{2}$. When the pressure reached stability, the solution was over-saturated for a short period of time until the formation of stable hydrate nuclei. In the hydrate growth stage, the pressure declined continuously, accompanied by a large heat release due to the growth of $\mathrm{CO}_{2}$ hydrates. The growth pattern of $\mathrm{CO}_{2}$ hydrate was not affected in the presence of SDS, which is consistent with the literature $[36,37]$. However, the induction time was significantly affected by the concentration of SDS. When the SDS concentration was less than $0.1 \%$, the induction time was reduced from 35 to $2 \mathrm{~min}$ with increasing SDS concentration. However, when the SDS concentration increased up to $0.05 \mathrm{wt} . \%$, the induction time of hydrate formation increased up to $0.10 \mathrm{wt} . \%$. Therefore, the $0.05 \mathrm{wt} . \%$ SDS concentration had the shortest induction time, and the promotion effect of $\mathrm{CO}_{2}$ hydrate formation was the most obvious. As a result of the salt removal effect of hydrate growth, water in the solution was consumed for hydrate growth, which resulted in an increased concentration of SDS and $\mathrm{NaCl} . \mathrm{NaCl}$ is a thermodynamic inhibitor; therefore, a high concentration of SDS will also inhibit the formation of hydrates. Thus, the formation effect of hydrate will change accordingly. This was consistent with the observations of Pahlavanzadeh et al. [38] and Partoon et al. [39]. The minimum concentration of surfactant micelle formation is the critical micelle concentration $(\mathrm{CMC})$. When the SDS concentration was higher than the CMC, the best effect of promoting hydrate formation was achieved.

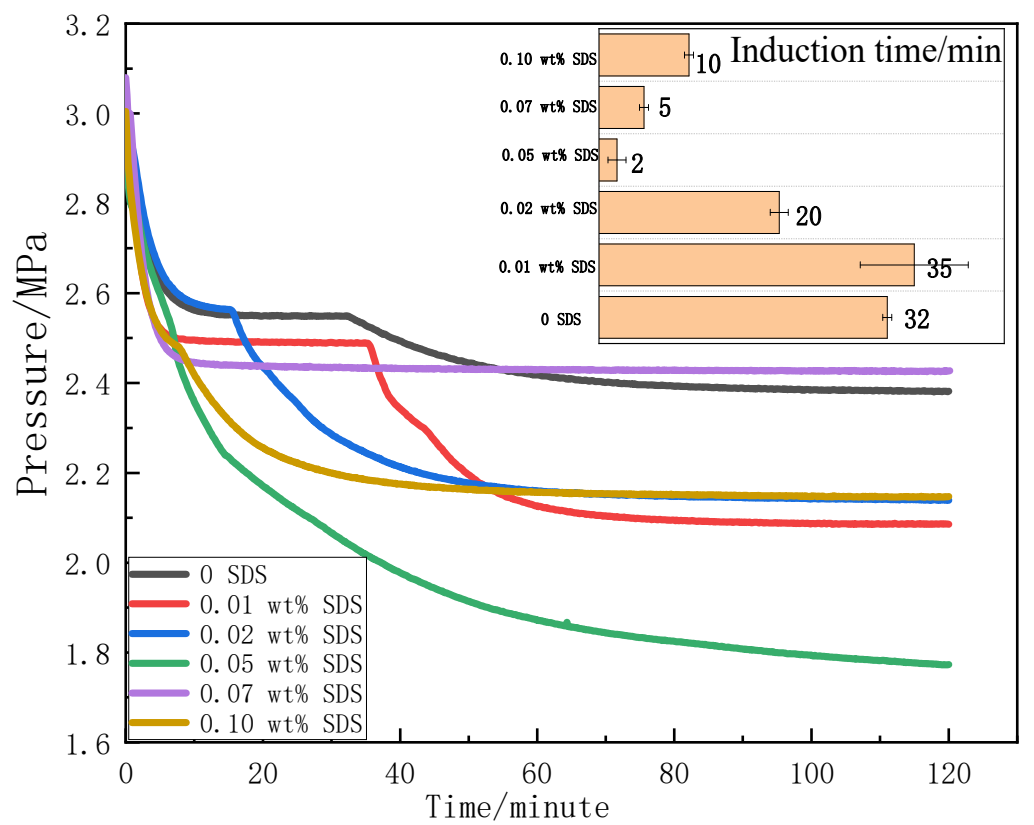

Figure 2. Pressure drop change induction time of hydrate formation in $3.5 \mathrm{wt} . \% \mathrm{NaCl}+\mathrm{SDS}$ solution.

Figure 3 shows the gas consumption and hydrate conversion during the formation of $\mathrm{CO}_{2}$ hydrate in the presence of $3.5 \mathrm{wt} . \% \mathrm{NaCl}$ and SDS. As shown, the hydrate conversion rate did not exceed $30 \%$ within 120 min because the hydrate growth in the late stage would be gradually influenced by gas diffusion in the hydrate phase [18]. The concentration of SDS had no evident influence on the gas solubility. However, the gas consumption continued to grow, and the hydrate conversion rate increased from 12.05 to $23.32 \%$ as the 
SDS concentration increased from 0 to $0.05 \mathrm{wt} . \%$. When the concentration of SDS increased to $0.10 \mathrm{wt}$. $\%$, the hydrate conversion rate of water also decreased from 23.32 to $15.28 \%$. Thus, it was suggested that $0.05 \mathrm{wt}$.\% SDS solution exhibited a good promotion effect on hydrate formation. In ref. [28], the hydrate formation in porous media was also found to be inhibited, as the SDS concentration surpassed $100 \mathrm{ppm}$ so that the observation in this work is generally in accord with the literature.

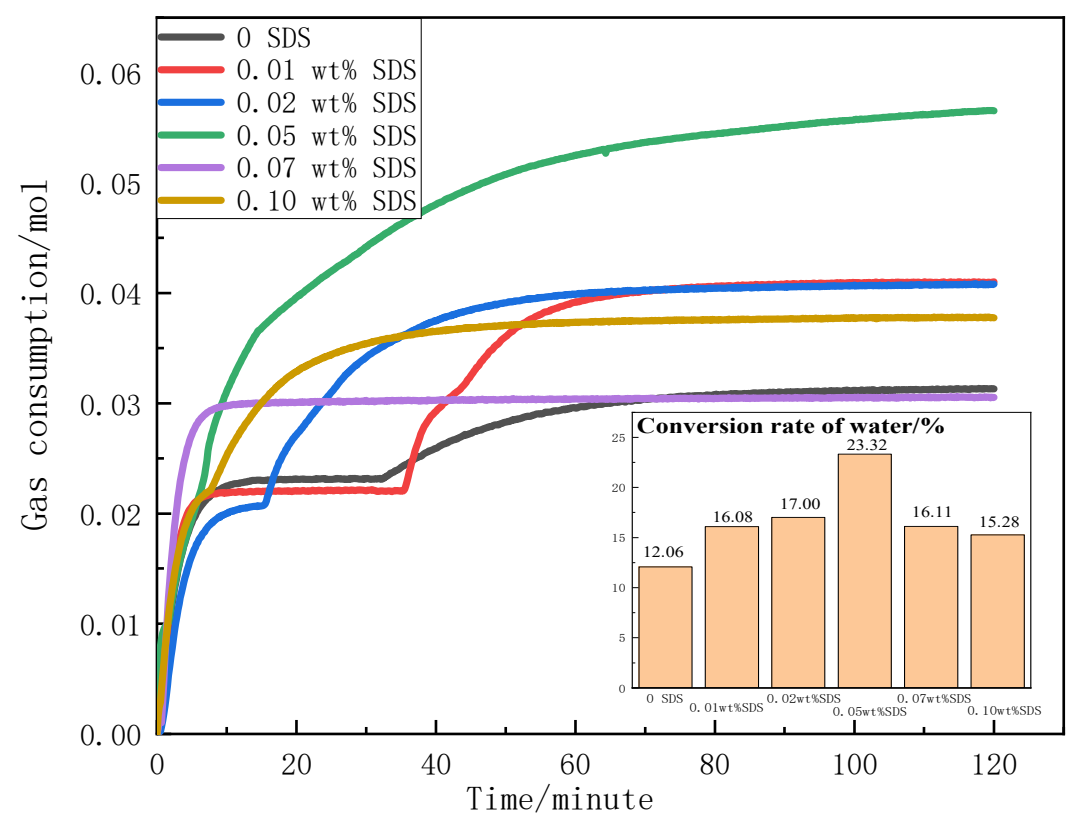

Figure 3. Gas consumption of hydrate formation and comparison diagram of hydrate conversion in $3.5 \mathrm{wt} . \% \mathrm{NaCl}$ and SDS solution.

Table 2 shows the concentration of $\mathrm{NaCl}$ after hydrate formation according to the gas consumption value of hydrate formation in $3.5 \% \mathrm{NaCl}+$ SDS solution, and the hydration number was 6.627. It is evident that when the SDS concentration is $0.05 \mathrm{wt} \%$, the concentration of remaining $\mathrm{NaCl}$ is the highest, reaching $4.515 \mathrm{wt}$ \%. However, the change in $\mathrm{NaCl}$ concentration is not obvious, which may be due to the over-strong promoting effect of SDS on the hydrate and the formation of overly dense hydrate at the liquid surface, which blocks the contact between $\mathrm{CO}_{2}$ and salt solution and further hinders the additional generation of hydrate, thus leading to a low desalination efficiency. By accelerating agitation, changing temperature, pressure conditions, and secondary hydration, the efficiency can be increased by approximately $50 \%$.

Table 2. Gas consumption and $\mathrm{NaCl}$ concentration after hydrate formation.

\begin{tabular}{|c|c|c|}
\hline System & $\mathrm{n} / \mathrm{mol}$ & wt./\% \\
\hline 3.5 wt. $\% \mathrm{NaCl}$ & 0.03130 & 3.997 \\
\hline 3.5 wt. $\% \mathrm{NaCl}+0.01$ wt. $\%$ SDS & 0.04102 & 4.182 \\
\hline 3.5 wt. $\% \mathrm{NaCl}+0.02$ wt. $\%$ SDS & 0.04102 & 4.178 \\
\hline 3.5 wt. $\% \mathrm{NaCl}+0.05$ wt. $\%$ SDS & 0.05655 & 4.515 \\
\hline 3.5 wt. $\% \mathrm{NaCl}+0.07$ wt.\% SDS & 0.03041 & 4.101 \\
\hline 3.5 wt. $\% \mathrm{NaCl}+0.10$ wt. $\%$ SDS & 0.03775 & 4.118 \\
\hline
\end{tabular}

\subsection{Microscopic Experiments}

\subsubsection{XRD}

$X$-ray diffraction (XRD) was used to characterize the XRD patterns of the $\mathrm{CO}_{2}$ hydrate formed by adding SDS to the $\mathrm{NaCl}$ solution. Figure 4 shows the diffraction pattern of the 
$\mathrm{CO}_{2}$ hydrate formed from the $\mathrm{NaCl}$ solution without SDS. The peaks at $2 \theta=27.0^{\circ}$ and $28.3^{\circ}$ correspond to the crystal planes (320) and (321) of the structure I hydrate. The peak intensities were not significant owing to the low hydrate conversion rate. Compared with the diffraction pattern of $\mathrm{CO}_{2}$ hydrate, the diffraction patterns of hydrates formed from the $\mathrm{NaCl}$ solution with SDS did not exhibit significant deviation in peak positions, as shown in Figure 5, suggesting that the structure of $\mathrm{CO}_{2}$ hydrate formed by adding $\mathrm{NaCl}$ solution with SDS was structure I, and the addition of different concentrations of SDS did not affect the structure of the $\mathrm{CO}_{2}$ hydrate crystals.

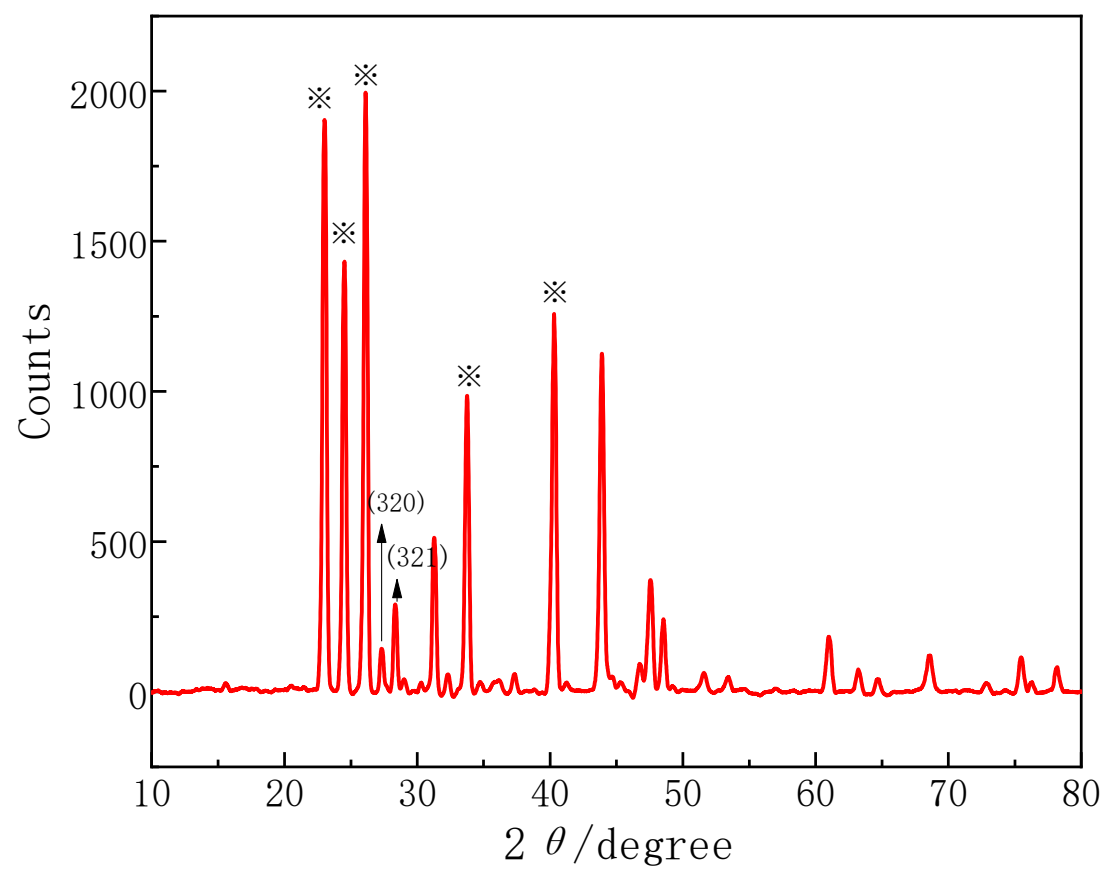

Figure 4. XRD patterns of $\mathrm{CO}_{2}$ hydrate formed by $3.5 \mathrm{wt} . \% \mathrm{NaCl}$ solution. Note: $※$ is the diffraction peak of ice.

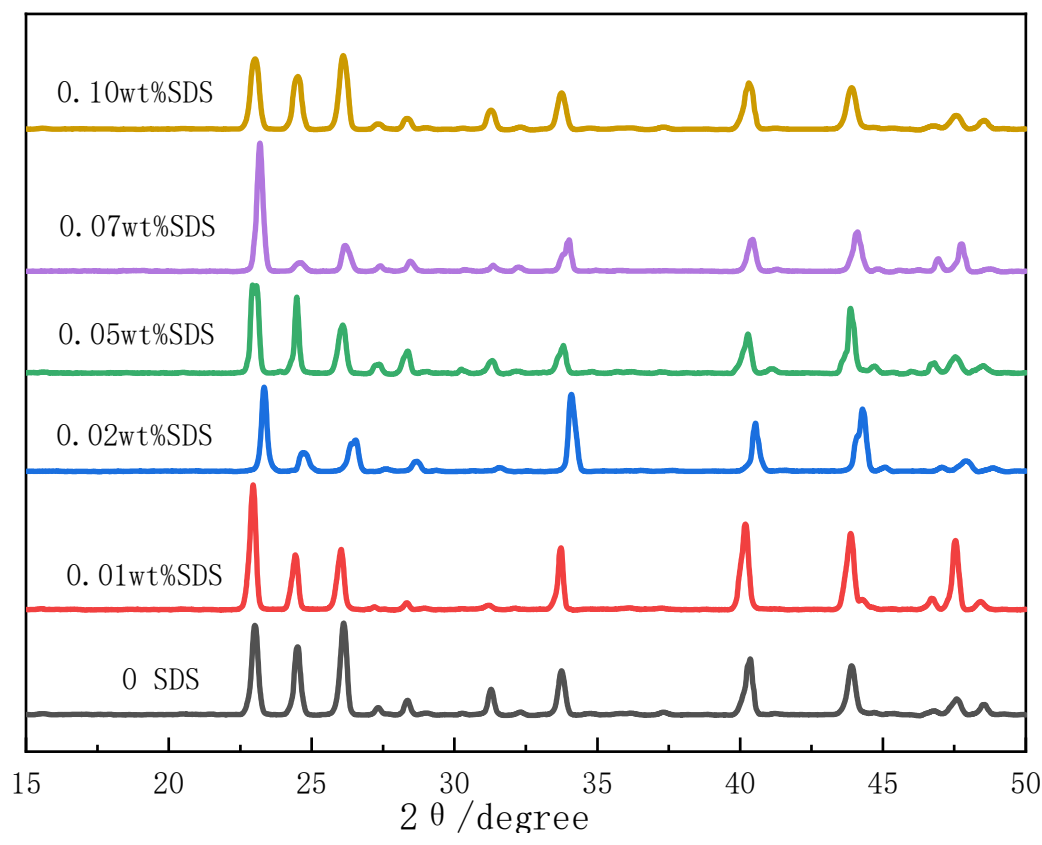

Figure 5. XRD patterns of $\mathrm{CO}_{2}$ hydrate generated by 3.5 wt. $\% \mathrm{NaCl}+\mathrm{SDS}$ solution. 
To study the uniformity of the hydrate distribution, the hydrate conversion rate $\mathrm{C}_{\mathrm{w} 1}$ obtained from macroscopic experiments and $\mathrm{C}_{\mathrm{w} 2}$, which was calculated from XRD based on semi-quantitative analysis, was compared. The hydration number, 6.627, was determined using the formula $46 \mathrm{H}_{2} \mathrm{O} \cdot 7.34 \mathrm{CO}_{2}$, which was obtained from the literature [40]. $\mathrm{C}_{\mathrm{w} 2}$ is the hydrate conversion rate calculated using HighScore Plus software, since the XRD patterns could also provide a quantitative analysis of phase volume [21]. Due to the certain resistance gas diffusion has in the liquid phase, the formation of the $\mathrm{CO}_{2}$ hydrate distribution is not uniform. In the XRD test, the hydrate samples were usually taken from the upper layer of the solid phase, which contained more hydrate phase. In this case, $\mathrm{C}_{\mathrm{w} 2}$ was generally larger than $\mathrm{C}_{\mathrm{w} 1}$, as shown in Table 3, suggesting that $\mathrm{CO}_{2}$ hydrate tended to concentrate at the gas-liquid interface instead of the liquid bulk.

Table 3. Conversion rate of water in macroscopic and microscopic experiments.

\begin{tabular}{|c|c|c|}
\hline System & $\mathrm{C}_{\mathrm{w} 1} / \%$ & $\mathrm{C}_{\mathrm{w} 2} / \%$ \\
\hline 3.5 wt. $\% \mathrm{NaCl}$ & 11.77 & 6.70 \\
\hline 3.5 wt. $\% \mathrm{NaCl}+0.01$ wt. $\%$ SDS & 15.34 & 34.7 \\
\hline 3.5 wt. $\% \mathrm{NaCl}+0.02$ wt. $\%$ SDS & 15.42 & 29.5 \\
\hline 3.5 wt. $\% \mathrm{NaCl}+0.05$ wt. $\%$ SDS & 21.26 & 30.0 \\
\hline 3.5 wt. $\% \mathrm{NaCl}+0.07$ wt. $\%$ SDS & 15.02 & 31.3 \\
\hline 3.5 wt. $\% \mathrm{NaCl}+0.10$ wt. $\%$ SDS & 14.19 & 36.1 \\
\hline
\end{tabular}

Note: $C_{w 1}$ is the conversion rate of water in the macroscopic experiment; $C_{w 2}$ is the conversion rate of water in the microscopic experiment.

\subsubsection{Cryo-SEM}

To further understand the influence of $\mathrm{NaCl}$ solution with added SDS on the microscopic features of $\mathrm{CO}_{2}$ hydrate, cryo-SEM was employed to show the micromorphology of the samples. All images were captured at a magnification of 5000 times. As shown in Figure 6a, the hydrate surface in the salt solution without SDS was smooth without folds; Figure $6 \mathrm{~b}$ shows that a significant crimp was observed on the surface of the hydrate formed by adding $0.01 \mathrm{wt} . \%$ SDS. In Figure $6 \mathrm{c}$, it is evident the surface of the hydrate formed by adding $0.02 \mathrm{wt} . \%$ SDS showed flake structure. Figure $6 \mathrm{~d}$ shows that when the SDS concentration was $0.05 \mathrm{wt} . \%$, an obvious rod structure on the surface was observed. As shown in Figure 6e, when the SDS concentration is $0.07 \mathrm{wt} . \%$, the hydrate surface shows a bubble structure. Figure $6 \mathrm{f}$ shows that when the concentration of SDS was $0.10 \mathrm{wt} . \%$, the hydrate surface presented cluster structure. From the figures, it is evident that with increasing concentration of SDS, the specific surface area increased. When the added SDS concentration is $0.05 \mathrm{wt} . \%$, at this point, the rod morphology can greatly improve the hydrate gas adsorption quantity of $\mathrm{CO}_{2}$ to accelerate hydrate formation. Therefore, the hydrate formation of gas consumption is the largest when SDS concentration is $0.05 \%$, consistent with the macroscopic experimental conclusion in Section 3.1. 

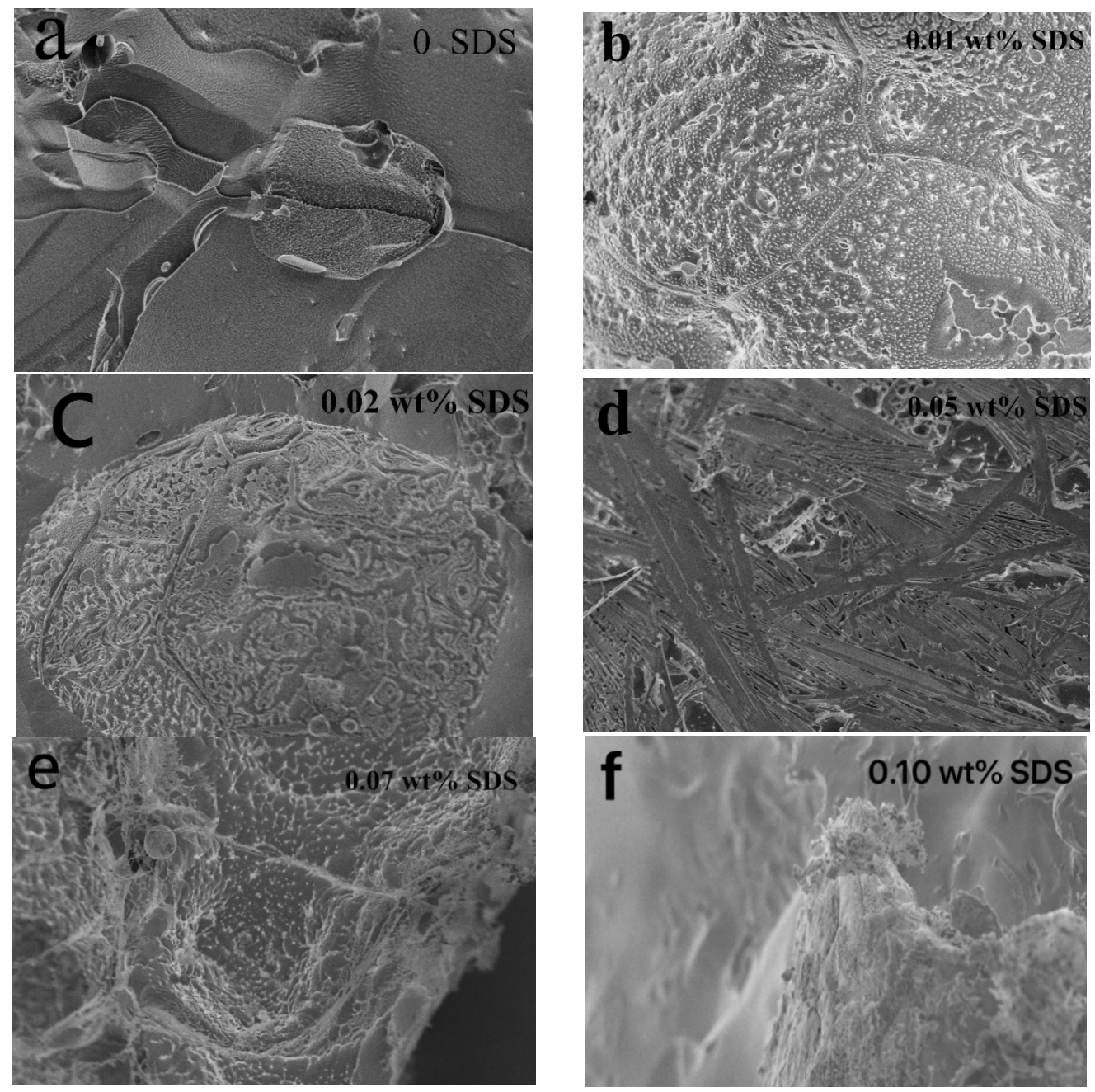

Figure 6. The pictures were observed by SEM for $\mathrm{CO}_{2}$ hydrate. (a) $0 \mathrm{wt} \% \mathrm{SDS}$ (b) $0.01 \mathrm{wt} \%$ SDS (c) $0.02 \mathrm{wt} \% \mathrm{SDS}$ (d) $0.05 \mathrm{wt} \% \mathrm{SDS}$ (e) $0.07 \mathrm{wt} \% \mathrm{SDS}$ (f) $0.10 \mathrm{wt} \% \mathrm{SDS}$

\section{Conclusions}

Improving the promotion effect of hydrates is very important for research on hydrate desalination. In this work, the effect of SDS added to a $3.5 \mathrm{wt} . \% \mathrm{NaCl}$ solution on the formation characteristics of $\mathrm{CO}_{2}$ hydrate was studied. The macroscopic kinetics and microscopic experiments of $\mathrm{CO}_{2}$ hydrate formation are investigated by adding $0.01,0.02$, $0.05,0.07$, and $0.10 \mathrm{wt} . \% \mathrm{SDS}$ to $3.5 \mathrm{wt} . \% \mathrm{NaCl}$ solution. From a theoretical perspective, kinetic experiments showed that the addition of SDS to a $3.5 \mathrm{wt} . \% \mathrm{NaCl}$ solution could reduce the induction time and increase the gas consumption and hydrate conversion rate, which is positively correlated with the concentration of SDS. When the concentration of SDS increased to $0.05 \mathrm{wt} . \%$, the effect of promoting the formation of $\mathrm{CO}_{2}$ hydrate was the most obvious. However, as the concentration of SDS reached $0.06 \%$, the promoting effect on hydrate formation was weakened. XRD analysis showed that the addition of SDS did not change the cage structure of the $\mathrm{CO}_{2}$ hydrate. Cryo-SEM revealed that SDS changed the surface morphology of the hydrate so that the specific surface area increased, thus improving the production of the hydrate.

Author Contributions: Conceptualization, D.L. and L.L.; methodology, X.Z.; investigation, L.L., Y.Z. and Y.Y.; writing-review and editing, L.L. All authors have read and agreed to the published version of the manuscript. 
Funding: This work was supported by the National Key Research and Development Plan of China (2017YFC0307306), National Natural Science Foundation of China (51876211, 51706230), Guangdong Natural Science Foundation (2020A1515010374, 2018B0303110007), Guangdong Special Support Program-Local innovation and entrepreneurship team project (2019BT02L278), Guangdong MEPP Fund (GDME-2018D002, GDOE[2019]A39, GDOE[2019]A54, GDOE[2019]A41).

Institutional Review Board Statement: Not applicable.

Informed Consent Statement: Not applicable.

Data Availability Statement: Not applicable.

Conflicts of Interest: The authors declare no conflict of interest. The funders had no role in the study design; in the collection, analyses, or interpretation of data; in the writing of the manuscript; or in the decision to publish the results.

\section{References}

1. Shannon, M.A.; Bohn, P.W.; Elimelech, M.; Georgiadis, J.G.; Marinas, B.J.; Mayes, A.M. Science and technology for water purification in the coming decades. Nature 2008, 452, 301-310. [CrossRef] [PubMed]

2. Khawaji, A.D.; Kutubkhanah, I.K.; Wie, J.M. Advances in seawater desalination technologies. Desalination 2008, 221, 47-69. [CrossRef]

3. Park, K.N.; Hong, S.Y.; Lee, J.W.; Kang, K.C.; Lee, Y.C.; Ha, M.G.; Lee, J.D. A new apparatus for seawater desalination by gas hydrate process and removal characteristics of dissolved minerals $\left(\mathrm{Na}^{+}, \mathrm{Mg}^{2+}, \mathrm{Ca}^{2+}, \mathrm{K}^{+}, \mathrm{B}^{3+}\right)$. Desalination 2011, 274, 91-96. [CrossRef]

4. Kalogirou, S.A. Seawater desalination using renewable energy sources. Prog. Energy Comb. Sci. 2005, 31, 242-281. [CrossRef]

5. Englezos, P. Clathrate hydrates. Ind. Eng. Chem. Res. 1993, 32, 1251-1274. [CrossRef]

6. Han, S.W.; Kim, W.; Lee, Y.; Jun, B.M.; Kwon, Y.N. Investigation of Hydrate-induced Ice Desalination (HIID) and its application to a pretreatment of reverse osmosis (RO) process. Desalination 2016, 395, 8-16. [CrossRef]

7. Hong, S.; Moon, S.; Lee, Y.; Park, Y. Investigation of thermodynamic and kinetic effects of cyclopentane derivatives on $\mathrm{CO}_{2}$ hydrates for potential application to seawater desalination. Chem. Eng. J. 2019, 363, 99-106. [CrossRef]

8. Han, S.; Rhee, Y.W.; Kang, S.P. Investigation of salt removal using cyclopentane hydrate formation and washing treatment for seawater desalination. Desalination 2017, 404, 132-137. [CrossRef]

9. Cha, J.H.; Seol, Y. Increasing Gas Hydrate Formation Temperature for Desalination of High Salinity Produced Water with Secondary Guests. ACS Sustain. Chem. Eng. 2013, 1, 1218-1224. [CrossRef]

10. Zhou, X.B.; Zhang, Y.; Zang, X.Y.; Liang, D.Q. Formation Kinetics of the Mixed Cyclopentane-Carbon Dioxide Hydrates in Aqueous Sodium Chloride Solutions. Energies 2020, 13, 4388. [CrossRef]

11. Babu, P.; Nambiar, A.; He, T.B.; Karimi, I.A.; Lee, J.D.; Englezos, P.; Linga, P. A review of clathrate hydrate based desalination to strengthen energy-water nexus. ACS Sustain. Chem. Eng. 2018, 6, 8093-8107. [CrossRef]

12. Babu, P.; Nambiar, A.; Chong, Z.R.; Daraboina, N.; Albeirutty, M.; Bamaga, O.A.; Linga, P. Hydrate-based desalination (HyDesal) process employing a novel prototype design. Chem. Eng. Sci. 2020, 218, 115563. [CrossRef]

13. He, T.B.; Nair, S.K.; Babu, P.; Linga, P.; Karimi, I.A. A novel conceptual design of hydrate based desalination (HyDesal) process by utilizing LNG cold energy. Appl. Energy 2018, 222, 13-24. [CrossRef]

14. Kang, K.C.; Linga, P.; Park, K.N.; Choi, S.J.; Lee, J.D. Seawater desalination by gas hydrate process and removal characteristics of dissolved ions $\left(\mathrm{Na}^{+}, \mathrm{K}^{+}, \mathrm{Mg}^{2+}, \mathrm{Ca}^{2+}, \mathrm{B}^{3+}, \mathrm{Cl}^{-}, \mathrm{SO}_{4}{ }^{2-}\right)$. Desalination 2014, 353, 84-90. [CrossRef]

15. Babu, P.; Kumar, R.; Linga, P. Unusual behavior of propane as a co-guest during hydrate formation in silica sand: Potential application to seawater desalination and carbon dioxide capture. Chem. Eng. Sci. 2014, 117, 342-351. [CrossRef]

16. Linga, P.; Clarke, M.A. A review of reactor designs and materials employed for increasing the rate of gas hydrate formation. Energy Fuels 2017, 31, 1-13. [CrossRef]

17. Li, X.S.; Xu, C.G.; Chen, Z.Y.; Wu, H.J. Tetra-n-butyl ammonium bromide semi-clathrate hydrate process for post-combustion capture of carbon dioxide in the presence of dodecyl trimethyl ammonium chloride. Energy 2010, 35, 3902-3908. [CrossRef]

18. Torre, J.P.; Ricaurte, M.; Dicharry, C.; Broseta, D. $\mathrm{CO}_{2}$ enclathration in the presence of water-soluble hydrate promoters: Hydrate phase equilibria and kinetic studies in quiescent conditions. Chem. Eng. Sci. 2012, 82, 1-13. [CrossRef]

19. Zhang, J.S.; Lee, J.W. Enhanced Kinetics of $\mathrm{CO}_{2}$ Hydrate Formation under Static Conditions. Ind. Eng. Chem. Res. 2009, 48, 5934-5942. [CrossRef]

20. Arora, A.; Cameotra, S.S.; Kumar, R.; Balomajumder, C.; Singh, A.K.; Santhakumari, B.; Kumar, P.; Laik, S. Biosurfactant as a Promoter of Methane Hydrate Formation: Thermodynamic and Kinetic Studies. Sci. Rep. 2016, 6, 1-13. [CrossRef]

21. Zhou, X.B.; Wan, L.H.; Long, Z.; Liang, D.Q. Kinetic measurements on $\mathrm{CO}_{2}$ adsorption and release using $\mathrm{TBAB}^{2} 38 \mathrm{H}_{2} \mathrm{O}$ hydrates as adsorbents. Energy Fuels 2019, 33, 6727-6733. [CrossRef]

22. Han, X.H.; Wang, S.J. Surfactant Accelerates Gas Hydrate Formation. In Proceedings of the 4th International Conference on Gas Hydrates, Yokohama, Japan, 19-23 May 2002; Volume 2, pp. 1036-1039. 
23. Jiang, L.L.; Li, A.R.; Xu, J.F.; Liu, Y.J. Effects of SDS and SDBS on CO(2)Hydrate formation, induction time, storage capacity and stability at 274.15 K and 5.0 MPa. Chemistryselect 2016, 1, 6111-6114. [CrossRef]

24. Molokitina, N.S.; Nesterov, A.N.; Podenko, L.S.; Reshetnikov, A.M. Carbon dioxide hydrate formation with SDS: Further insights into mechanism of gas hydrate growth in the presence of surfactant. Fuel 2019, 235, 1400-1411. [CrossRef]

25. Dicharry, C.; Duchateau, C.; Asbai, H.; Broseta, D.; Torre, J.P. Carbon dioxide gas hydrate crystallization in porous silica gel particles partially saturated with a surfactant solution. Chem. Eng. Sci. 2013, 98, 88-97. [CrossRef]

26. Gayet, P.; Dicharry, C.; Marion, G.; Graciaa, A.; Lachaise, J.; Nesterov, A. Experimental determination of methane hydrate dissociation curve up to $55 \mathrm{MPa}$ by using a small amount of surfactant as hydrate promoter. Chem. Eng. Sci. 2005, 60, 5751-5758. [CrossRef]

27. Link, D.D.; Ladner, E.P.; Elsen, H.A.; Taylor, C.E. Formation and dissociation studies for optimizing the uptake of methane by methane hydrates. Fluid Phase Equilibria 2003, 211, 1-10. [CrossRef]

28. Kang, S.P.; Lee, J.W. Kinetic behaviors of $\mathrm{CO}_{2}$ hydrates in porous media and effect of kinetic promoter on the formation kinetics. Chem. Eng. Sci. 2010, 65, 1840-1845. [CrossRef]

29. Zhang, J.S.; Lo, C.; Somasundaran, P.; Lee, J.W. Competitive adsorption between SDS and carbonate on tetrahydrofuran hydrates. J. Colloid Interface Sci. 2010, 341, 286-288. [CrossRef]

30. Torre, J.P.; Dicharry, C.; Ricaurte, M.; Daniel-David, D.; Broseta, D. $\mathrm{CO}_{2}$ capture by hydrate formation in quiescent conditions: In search of efficient kinetic additives. In 10th International Conference on Greenhouse Gas Control Technologies; Gale, J., Hendriks, C., Turkenberg, W., Eds.; Elsevier Science BV: Amsterdam, The Netherlands, 2011; Volume 4, pp. 621-628.

31. Sun, J.Y.; Li, C.F.; Hao, X.L.; Liu, C.L.; Chen, Q.; Wang, D.G. Study of the surface Morphology of Gas Hydrate. J. Ocean Univ. China 2020, 19, 331-338. [CrossRef]

32. Yi, L.Z.; Zhao, L.L.; Tao, S.H. Methane hydrate formation in an oil-water system in the presence of lauroylamide propylbetaine. RSC Adv. 2020, 10, 12255-12261. [CrossRef]

33. Zhou, X.B.; Zang, Q.; Long, Z.; Liang, D.Q. In situ PXRD analysis on the kinetic effect of PVP-K90 and PVCap on methane hydrate dissociation below ice point. Fuel 2021, 286, 119491. [CrossRef]

34. Schicks, J.M.; Ripmeester, J.A. The Coexistence of Two Different Methane Hydrate Phases under Moderate Pressure and Temperature Conditions: Kinetic versus Thermodynamic Products. Angew. Chem. Int. Ed. 2004, 43, 3310-3313. [CrossRef] [PubMed]

35. Zhou, X.B.; Liang, D.Q. Enhanced performance on $\mathrm{CO}_{2}$ adsorption and release induced by structural transition that occurred in TBAB $26 \mathrm{H}_{2} \mathrm{O}$ hydrates. Chem. Eng. J. 2019, 378, 122128. [CrossRef]

36. Zhong, Y.; Rorges, R.E. Surfactant effects on gas hydrate formation. Chem. Eng. Sci. 2000, 55, 4175-4187. [CrossRef]

37. Rorges, R.E. Chemical Engineering. U.S. Patent 6389820, 21 May 2002.

38. Pahlavanzadeh, H.; Khanlarkhani, M.; Rezaei, S.; Mohammadi, A.H. Experimental and modelling studies on the effects of nanofluids $\left(\mathrm{SiO}_{2}, \mathrm{Al}_{2} \mathrm{O}_{3}\right.$, and $\left.\mathrm{CuO}\right)$ and surfactants (SDS and $\mathrm{CTAB}$ ) on $\mathrm{CH} 4$ and $\mathrm{CO}_{2}$ clathrate hydrates formation. Fuel 2019, 253, 1392-1405. [CrossRef]

39. Partoon, B.; Malik, S.N.A.; Azemi, M.H.; Sabil, K.M. Experimental investigations on the potential of SDS as low-dosage promoter for carbon dioxide hydrate formation. Asia-Pac. J. Chem. Eng. 2013, 8, 916-921. [CrossRef]

40. Henning, R.W.; Schultz, A.J.; Thieu, V. Neutron diffraction studies of $\mathrm{CO}_{2}$ clathrate hydrate: Formation from deuterated ice. J. Phys. Chem. A 2000, 104, 5066-5071. [CrossRef] 